\title{
PRICE-SETTING POLICY DETERMINANTS: MICRO-EVIDENCE FROM BRAZIL *
}

\author{
Marcelo L. Moura ${ }^{\dagger}$ \\ José LuIz RossI JÚNIOR ‡
}

\begin{abstract}
The paper studies the frequency of price changes from a survey data on Brazilian companies. The data set has the advantage of including all of the economic sectors: agricultural and food products, trading, industry and services. Strong evidence of nominal price rigidities is found on the data with average and median price durations around 10.1 and 8.1 months, which is very close to results reported for the euro area and the United States. Using econometric modeling through an ordered probit and also an OLS regression, we find that price change duration is mostly explained by the wage duration, the degree of competition, product specialization, the elasticity of demand and economic sector dummies. The empirical results refute somewhat commonly used macroeconomic modeling for monetary policy evaluation; however they do not refute timedependent models since those are consistent with different price durations across firms. These results shed light on some stylized facts that a macroeconomic price-setting model would need to reproduce.
\end{abstract}

Keywords: price-setting; frequency of price changes; nominal rigidities; sticky prices; survey data.

JEL classification: E31, D40.

\section{Introduction}

Price stickiness and nominal rigidities play a central role in modern macroeconomic models. For instance, as emphasized by Gali \& Gertler (2007), the baseline model for monetary policy evaluation relies on the assumption that firms set prices individually on a staggered basis. Usually, a Calvo (1983) formulation is used, where at each period there is a fixed probability that a given firm will change its price independent of its history. Although this formulation simplifies aggregation across firms and produces parsimonious aggregate supply curves, there is increasingly empirical micro evidence that price changes does not operate in this way.

The validity of those theoretical results has recently been studied empirically by the Inflation Persistence Network (IPN) of the European Central

\footnotetext{
* The authors would like to thank many helpful comments from an anonymous referee and Tânia de Toledo Lima for excellent research assistance.

† Insper Instituto de Ensino e Pesquisa, email: marcelom@insper.edu.br.

‡ Insper Instituto de Ensino e Pesquisa, email: joselrj1@insper.edu.br
} 
Bank. Angeloni et al. (2006) compare recent microevidence with the main macro models used in monetary policy analysis. Their results indicate that these models are seriously challenged by stylized facts on price-setting practices and inflation persistence. Alvarez et al. (2006) summarizes micro evidence regarding price-setting policies from the analysis of panel quotes of consumer and producer prices and surveys. Their general results points to some stylized facts: i) firms change price infrequently, on average once a year; ii) price-setting behavior is heterogeneous across firms; iii) implicit or explicit contracts and coordination failure theories are important; and iv) downward price rigidity is slightly higher than upward rigidity.

The main goal of this paper is to explore the first two stylized facts presented by Alvarez et al. (2006). Our central questions are: is there evidence of stickiness in Brazilian companies' pricing policies? If the answer is yes, how is the frequency of price changes influenced by firms' heterogeneity? The paper is structured as follows. Section 2 introduces a theoretical discussion concerning price stickiness and some of the control variables used in this study. Section 3 presents the data used in the analysis and investigates the evidence for price stickiness. Section 4 studies the empirical determinants of the durations of price changes. Section 5 concludes.

\section{Theoretical basis}

New-Keynesian macroeconomic models usually incorporate price stickiness into the baseline model through an assumption of exogenous price changes, as in Calvo's 1983 staggered price-setting model ${ }^{1}$. In Calvo's 1983 model, in each period a fraction $\theta$ of firms, $0<\theta<1$, reset prices, and a fraction $1-\theta$ of firms keep prices unchanged for at least one additional period. Assuming monopolistic competition, the problem that a particular firm faces when it has the opportunity to change its price level is to make this choice by maximizing profits during the time when prices are expected to be kept fixed. The problem can be formalized as

$$
\max _{p_{t}^{*}} \sum_{k=0}^{+\infty} \theta^{k}\left\{\beta^{k}\left[p_{t}^{*} y_{t+k \mid t}-C\left(y_{t+k \mid t}\right)\right]\right\},
$$

subject to

$$
y_{t+k \mid t}=k p_{t}^{-\varepsilon},
$$

where, in equation (1), $p_{t}^{*}$ is the optimal chosen price level, $\beta$ is the time discount factor, $y_{t+k \mid t}$ is the expected production level in $t+k$, given information

\footnotetext{
${ }^{1}$ Accordingly to Gali \& Gertler (2007) who summarize the macroeconomic modeling widespread used by central banks and academics from the late nineties to the time the paper was published, Calvo (1983) model still is used as a reasonable assumption in the macroeconomic models and as an reasonable approximation of the data. More particularly, they say: "The aggregate supply relation evolves from the price-setting decisions of individual firms. To capture nominal price inertia, it is assumed that firms set prices on a staggered basis: each period a subset of firms set their respective prices for multiple periods. Under the most common formulation, due to Calvo(1983), each period a firm adjusts its price with a fixed probability that is independent of history. 4 This assumption is not an unreasonable approximation of the evidence (Nakamura and Steinsson, 2007; Alvarez, 2007)." Notice that the updated reference for the last two papers cited above are Nakamura \& Steinsson (2008) and Alvarez \& Julián (2008).
} 
available at time $t$ and $C(\cdot)$ is the firm's cost function, which is increasing, convex and twice differentiable. Equation (2) is the demand equation, where $k$ is an arbitrary constant and $\varepsilon$, is the constant elasticity of demand. In order to have a well-defined maximization problem, we assume $\varepsilon>1$,

The solution for the problem stated in (1) and (2) gives the first-order condition:

$$
\sum_{k=0}^{+\infty} \theta^{k}\left\{\beta^{k} y_{t+k \mid t}\left[p_{t}^{*}-\mu \frac{\partial C\left(y_{t+k \mid t}\right)}{\partial y_{t+k \mid t}}\right]\right\}=0,
$$

where $\mu=\varepsilon /(\varepsilon-1)$ is the mark-up, a decreasing function of the demand elasticity parameter, $\varepsilon$. Notice that, given that $\varepsilon>1$, the mark-up is always positive and greater than one.

Consider the special case where firms have the opportunity to change prices every period, this is the case of no price rigidities, with $\theta=0$. From equation (3), it is easy to see that in this case the optimal price-setting will imply a constant price mark-up over the marginal cost, that is,

$$
p_{t}^{*}=\frac{\varepsilon}{\varepsilon-1} \frac{\partial C\left(y_{t}\right)}{\partial y_{t}}
$$

The expression in equation (4) gives an interesting benchmark case for our theoretical discussion. In the absence of rigidities, prices will change in response to changes in marginal costs or demand elasticity.

Although theoretically interesting, the equilibrium condition under flexible prices does not appear to be realistic. Empirical surveys indicate strong evidence of price rigidities. Consistently with the IPN studies, like in Alvarez et al. (2006), retail price duration in the euro area is around four to five quarters while in the United States is around two quarters. The same study indicates that the main reasons for price stickiness are the existence of implicit or explicit contracts and strategic interactions among competing firms.

Building models with endogenous price-setting rules is no simple task. Many have been developed that produce no straightforward equilibrium conditions; see, for instance, Romer (1990), Kiley (2000) and Bonomo \& Carvalho (2004). In general, those models allow firms to choose optimally the probability parameter of price changes, $\theta$, implying an average price duration of $1 / \theta$. Those models associate price changes with macroeconomic conditions; in general, longer durations are observed with lower money growth rates and lower price variability. However, those models present no link with such microeconomic conditions as demand elasticity, number of competitors or specialization in one product, characteristics that our empirical study aims to investigate.

We do not intend to develop an endogenous price-setting model in this section. Instead, our goal is simply to discuss some theoretical implications of this price-setting model ${ }^{2}$. In particular, we are interested in the shape of the profit function with regard to the elasticity of demand. We do this by looking at the profit loss by not adjusting prices and using comparative statics to see how this profit loss depends on the elasticity of demand.

For instance, assume that at some period, there is an incentive for the firm's adjusting its price to the optimal level $p^{*}$, given by (4), but instead,

\footnotetext{
${ }^{2}$ We thank an anonymous referee for very useful insights in this section.
} 
the firm decides to keep prices fixed at $p^{*}+\Delta p$. Consider this profit loss denoted as $x_{t} \equiv \pi\left(p^{*}+\Delta p\right)-\pi\left(p^{*}\right)$; a Taylor second-order approximation implies that

$$
\begin{aligned}
x_{t} & \left.\simeq \frac{\partial \pi}{\partial p}\right|_{p=p^{*}} \Delta p+\left.\frac{1}{2} \frac{\partial^{2} \pi}{\partial p^{2}}\right|_{p=p^{*}}(\Delta p)^{2} \\
& =\left.\frac{1}{2} \frac{\partial^{2} \pi}{\partial p^{2}}\right|_{p=p^{*}}(\Delta p)^{2} \\
& =-K(\Delta p)^{2}<0,
\end{aligned}
$$

where the second equality uses the first-order condition of profit maximization and the last one uses the second-order condition for a maximum, where $K$ is a positive constant. From equation (4), we notice that changes in prices are motivated only by changes in marginal costs, assuming a constant elasticity of demand for a given firm. Thus, substituting this into equation (5), we have

$$
x_{t}=-K\left(\frac{\varepsilon}{\varepsilon-1}\right)^{2}\left(\Delta \frac{\partial C\left(y_{t}\right)}{\partial y_{t}}\right)^{2} .
$$

Specifically, if we are interested in the effect of the elasticity of demand on net losses

$$
\frac{\partial x_{t}}{\partial \varepsilon}=\frac{2 K}{(\varepsilon-1)^{2}}\left(\frac{\varepsilon}{\varepsilon-1}\right)\left(\Delta \frac{\partial C\left(y_{t}\right)}{\partial y_{t}}\right)^{2}>0 .
$$

This result implies that as the elasticity of demand increases, so do real net losses as a result of not adjusting prices. Assuming that there is a fixed cost in adjusting prices, the menu costs hypothesis, it is more likely that firms facing higher demand elasticity will be more inclined to change prices. Therefore, our first theoretical assumption is that firms with higher elasticity of demand will change prices more frequently, implying lower price durations. We will test this assumption empirically in section 4 .

Another assumption we will test empirically concerns the relationship among the degree of concentration in the industry, measured by market share, the number of competitors, and price duration. The link we make is through the elasticity of demand. From our result in equation (4), we see that a lower elasticity implies a higher mark-up and consequently greater market power we expect will be wielded by the firm. Thus, our second theoretical assumption is: the higher the market power, the lower the elasticity of demand and consequently the higher the price duration.

Equation (6), shows that the profit loss depends on changes in marginal cost. However, the marginal cost also depends on the technology and the cost function. Since we have no information about the exact format of the cost function of each firm, we opt for an indirect approach to control price adjustments to the cost effects. We do this by relating the profit or loss to known effects of scale and scope. Economies of scale are defined by Panzar \& Willig (1977) when "a small pro-portional increase in the levels of all input factors can lead to more than proportional increases in the levels of outputs produced." Regarding economies of scope, the definition given in Panzar \& Willig 
(1981) is that there are economies derived from producing two or more product lines in one firm rather than producing them separately. Thus, in our final theoretical assumption, we assume that, in the presence of economies (diseconomies) of scale and scope, the production level and the degree of product specialization affects the frequency of price-setting. However, we make no assumption with regard to whether scale and scope have a positive or negative impact on price frequency.

\section{Data}

We looked at a survey of 281 Brazilian firms organized by the research department of Ibmec São Paulo and conducted by Sensus, a market and opinion research institute. The survey was conducted from the 3 rd to the 28 th of September 2007; questions were asked taking as reference the year of 2007, unless otherwise indicated. The sample was selected by using the same companies surveyed by Gazeta Mercantil, one of the major business newspapers in Brazil, in order to keep track of financial data of those companies and also to have a representative sample of the major business sectors of the Brazilian economy. In this way, we were able to merge data from the two independent surveys.

Table 1 presents the defined variables that we employed in our analysis. Motivated by the theoretical discussion in section 2 and the existent literature, we selected the wage-change duration as a proxy for cost structure; the market share or number of competitors, the level or degree of concentration in the industry; the log of net revenues, for scale effects; the proportion of a firm's flagship product within total sales, for economies of scope and demand elasticity for market conditions and mark-up effects. Notice that for multiproduct firms, the interviewer of the survey asked the interviewee to consider only the main product of the firm, the product that represents the highest percentage of total sales. Those variables were drawn from a larger questionnaire involving a total of 90 questions. In the majority of cases, questions were answered at the company site by the CEO, the CFO, the director, or the financial manager.

Table 2 presents summary statistics for our variables of interest. Of note is that price average and median durations for 2006/07 in Brazil are surprisingly high; the mean is 10.06 months, and the median is 12 months. Although Brazil has historically had very high inflation, particularly from 1980 to 1994, with yearly rates above $100 \%$, we detect, for the year 2007, price durations in Brazil to be quite similar to those of the euro area and even higher than in the United States. Álvarez et al. (2006) report that for the euro area and the United States, the respective mean-price durations are 10.8 and 8.3 months. This is in accordance with the fact that CPI growth in the Brazilian economy was only $3.1 \%$ in 2006 and $4.5 \%$ in 2007, representing inflation rates just slightly above the euro area and US standards.

This result is similar to that of Gagnon (2007), who studies price-setting in the Mexican economy and finds that for annual inflation rates below $10 \%$, price average durations in Mexico are very close to US values. For the Brazilian economy, Gouvea (2007) uses an extensive dataset of CPI price quotes from 1996 to 2006 and reports a lower price duration, around 3 to 4 months, than the value we found. It is worth noting that Gouvea (2007) incorporates 
Table 1: Variable definitions.

\begin{tabular}{|c|c|c|}
\hline Variable & Survey question & Answer \\
\hline Price change duration & $\begin{array}{l}\text { 'With what frequency does } \\
\text { your company change } \\
\text { prices?' }\end{array}$ & $\begin{array}{l}\text { Open answer, number of } \\
\text { months. }\end{array}$ \\
\hline Wage change duration & $\begin{array}{l}\text { 'With what frequency does } \\
\text { your company change } \\
\text { wages?' }\end{array}$ & $\begin{array}{l}\text { Open answer, number of } \\
\text { months. }\end{array}$ \\
\hline Market share & $\begin{array}{l}\text { 'What was the market share } \\
\text { of your main product in } \\
\text { 2006?' }\end{array}$ & Open answer, \\
\hline Log Net revenue $(\mathrm{R} \$)$ & $\begin{array}{l}\text { 'What were the total net } \\
\text { sales of your company in } \\
\text { 2006?' }\end{array}$ & $\begin{array}{l}\text { Open answer, thousands of } \\
\text { Brazilian reais }(\mathrm{R} \$) \text {. }\end{array}$ \\
\hline $\begin{array}{l}\text { Participation of the main } \\
\text { product }\end{array}$ & $\begin{array}{l}\text { 'What is the percentage of } \\
\text { your main product in total } \\
\text { sales?' }\end{array}$ & Open answer, \\
\hline Number of Competitors & $\begin{array}{l}\text { 'How many competitors are } \\
\text { in the market occupied by } \\
\text { your main product?' }\end{array}$ & $\begin{array}{l}\text { Open answer, discrete num- } \\
\text { ber. }\end{array}$ \\
\hline Demand Elasticity & $\begin{array}{l}\text { 'All else being equal, in } 2006 \text {, } \\
\text { if you increase your price by } \\
10\end{array}$ & \\
\hline
\end{tabular}

Source: Ibmec São Paulo / Sensus Brazilian Companies Survey

Note: Values were converted to numbers: option (a) is 0 ; option (b) is 2; option (c) is 4; options (d) and (e) are 8.

a much larger period than ours, encompassing a period during which inflation was more volatile. In fact, she finds that decreases in price durations occurred when the economy was hit by confidence shocks, as in 2002, when inflation hiked to $12.6 \% .^{3}$ Barros et al. (2009) als studies price setting in Brazil with particular interest on the effect of variable macroeconomic conditions, as market crises, change in exchange rate and monetary regimes and others. They use an unique data set from the Brazilian CPI index of Fundação Getulio Vargas with individual price-quotes from 1996-2008. Their findings also go in the same direction than the others cited above in the sense that price increases are more frequent with higher inflation, exchange rate depreciation, higher economic activity and uncertainty. ${ }^{4}$

Regarding the other variables in table 2 , we find that wage-change duration is closely matched by the mean and median values for price changes; it has, however, much lower variability. With respect to competition variables, we find the market share and the number of competitors indicating the presence of strong concentration in Brazilian companies; the median firm, for its main product, has around $30 \%$ of the market and 5 competitors. Mean and

\footnotetext{
${ }^{3}$ In fact, countries with a history of high inflation, like Brazil and Mexico in the 1980s and the first half of the nineties might be associated with a lack of an anti-inflation culture. Although testing for the presence of an anti-inflation culture after price stabilization in Brazil, after 1994, would be interesting to undertake, we currently do not have the large data span necessary to test it. We thus leave this point for further research.

${ }^{4}$ We thank an anonymous referee for remembering us about the existence of a large body of literature for Brazil during the late eighties up to mid nineties attempting to test the relationship between inflation and relative price dispersion. Those studies found that higher inflation increases relative price dispersion. We omit those citations here to save space.
} 
Table 2: Summary statistics

\begin{tabular}{lcccccc}
\hline \multicolumn{1}{c}{ Variable } & Median & Mean & Std. Dev. & Max. & Min. & Obs. \\
\hline Price-change duration & 12 & 10.4 & 8.1 & 60 & 1 & 195 \\
Wage-change duration & 12 & 11.7 & 2.1 & 24 & 3 & 255 \\
Market share & 30 & 35.7 & 32.3 & 100 & 0.000 & 154 \\
Log net revenue & 10.2 & 10 & 2.3 & 16.8 & 3.2 & 181 \\
Revenue & 26089 & 240174 & 1278565 & 19200000 & 25 & 181 \\
\% main product & 75 & 68.6 & 30.2 & 100 & 1 & 109 \\
Numb. of competitors & 5 & 16.4 & 27.6 & 98 & 0 & 211 \\
Demand elasticity & 2 & 2.1 & 1.7 & 8 & 0.5 & 236 \\
\hline
\end{tabular}

Source: Ibmec São Paulo / Sensus Brazilian Companies Survey

Net revenue in multiples of $\mathrm{R} \$ 1,000.00$ - approximately US\$600.00, according to average quotes as of April 2007.

median values for the main product's percentage of total sales indicate that Brazilian companies are generally not very diversified across products. The average demand elasticity demonstrates that the majority of Brazilian companies are in the elastic region of their demand curves. The number of observations across variables varies, owing to the lack of available responses to some questionnaires. Recall that, as was expressly mentioned in the questionnaire, all variables refer to the main product of each firm, which is the product responsible for the most sales.

Table 3 presents the correlations across our variables of interest. In our theoretical discussion in section 2 , we noted our expectation that price change duration would be positively correlated to cost changes and market power. This hypothesis is partially confirmed with positive and statistically significant correlations among price durations with wage-change durations and market share. Specialization (\% main product) also has a positive and significant correlation with price duration, indicating possible diseconomies of scope, as price changes depend on the slope of the cost curve; see equation - Finally, in section 2, we also mentioned that demand elasticity would be negatively associated with market power; this is confirmed by the negative correlation of demand elasticity with market share and a positive correlation with the number of competitors.

The stylized fact mentioned by Alvarez et al. (2006) regarding price adjustments being heterogeneous across sectors is replicated in our survey. Table 4 displays data on price frequencies across sectors and compares them with euro-area and US data. From this, we can see a strong heterogeneity across sectors that are closely matched by euro area and US data. In general, the trading sector has longer price durations, followed by agricultural and food products. Industry and services have the longest durations and consequently lower price frequencies.

In summary, we can associate three stylized facts with our data. First, prices are indeed sticky and have high average durations. Second, data is coherent with our theoretical hypothesis in section 2. Third, price-changing decision-rules are very heterogeneous across firms. We now turn to the question of price-change determinants. 


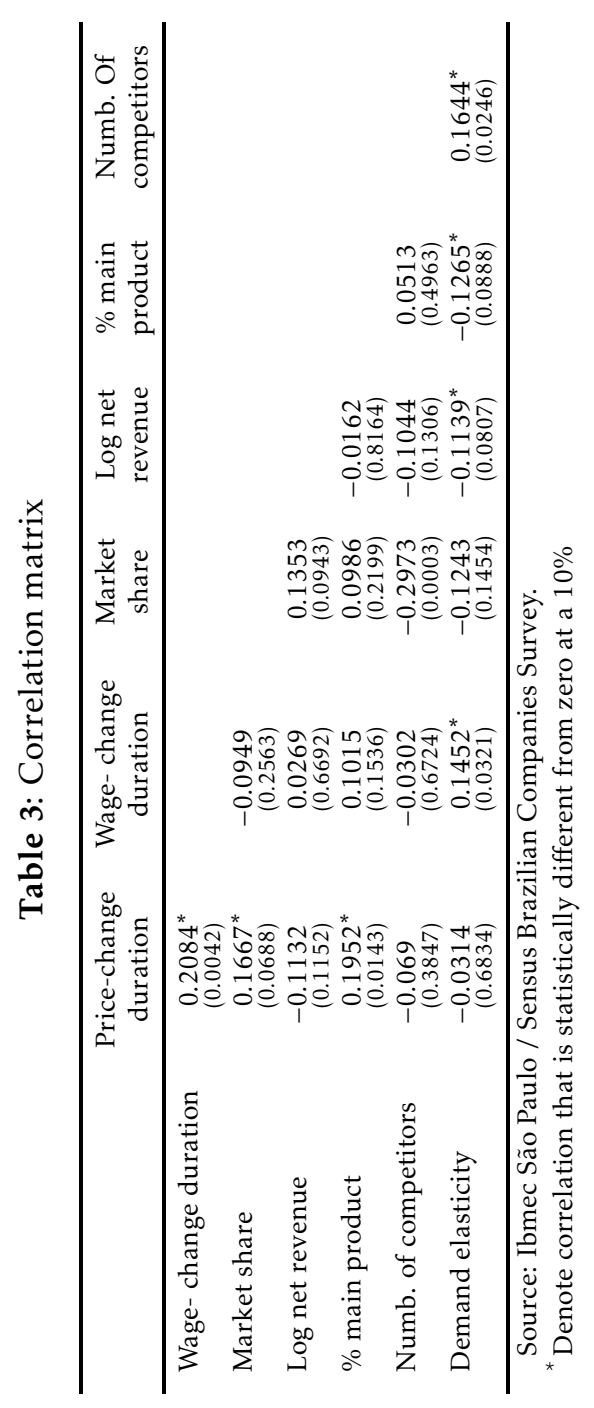




\section{Determinants of price durations}

In this section, we aim to model the firm's decision regarding price changes as a function of market characteristics. Motivated by our theoretical discussion in section 2, we selected as potential explanatory variables the wage change duration, as a proxy for cost structure; market share or number of competitors, for competition level; log of net revenues, for scale; proportion of the main product as part of total sales, for economy of scope effects and demand elasticity for market conditions. We also used a dummy for economic sectors in order to capture all other market specificities not captured by the previous variables.

Since our dependent variable is a discrete ordered variable, we employ an ordered qualitative response model for the price change frequency. In particular, we apply an ordered probit model, where if $y_{i}$ is the price duration choice of firm $i$ and $X_{i}$ denotes the vector of firm's $i$ characteristics, then the probability of $y_{i}$ assuming a given discrete value $J=0,1,2, \ldots, 12, \ldots, 60$ is

$$
\operatorname{Pr}\left(y_{t}=J\right)=\operatorname{Pr}\left(y_{t}^{*}<\gamma_{J}\right)=\operatorname{Pr}\left(X_{i} \beta+u_{i}<\gamma_{J}\right),
$$

Where $\beta$ and $\gamma_{J}, J=0,1,2, \ldots, 12, \ldots, 60$ are the estimated parameters.

Although discrete, our dependent variable is nearly a continuous variable. Therefore, on order to test for the robustness of our results and also to make coefficients easier to interpret, we also adopt a continuous model:

$$
y_{t}=\alpha+X_{i} \beta+u_{i}
$$

The regression model in (9) is estimated using ordinary least squares.

Table 5 reports our empirical results for the ordered probity model, equation (8), and Table 6 reports results for the continuous variable model, equation (9). In the two models, the results are basically the same.

The coefficient for wage-duration changes has the expected positive sign but is not statistically significant in some specifications. As predicted in the theoretical discussion a higher competition level leads to a lower price duration; coefficients for market share are positive and significant in seven out of eight specifications, and coefficients for the number of competitors are negative but not significant. Larger firms will also change prices more regularly, although the coefficient is significant for just one specification in each regression model.

The level of specialization in production also seems to play an important role, as firms more devoted to one product will have higher durations and change their prices less frequently. As mentioned before, this is indicative of the presence of diseconomies of scope. The result of the demand elasticity coefficient also matches the theoretical assumption that higher demand elasticity increases real net losses by not adjusting prices and consequently decreases price durations; see equation (7). The demand elasticity coefficient is mostly negative and is statically significant in four out of eight cases. As expected from the analysis of section 4 , the industrial and service sectors have significantly higher price duration than that shown by the other sectors, trade and agribusiness.

As a final comment, our results corroborate the empirical results of Hoeberichts \& Stockman (2004) for Dutch companies, and Alvarez \& Hernando 


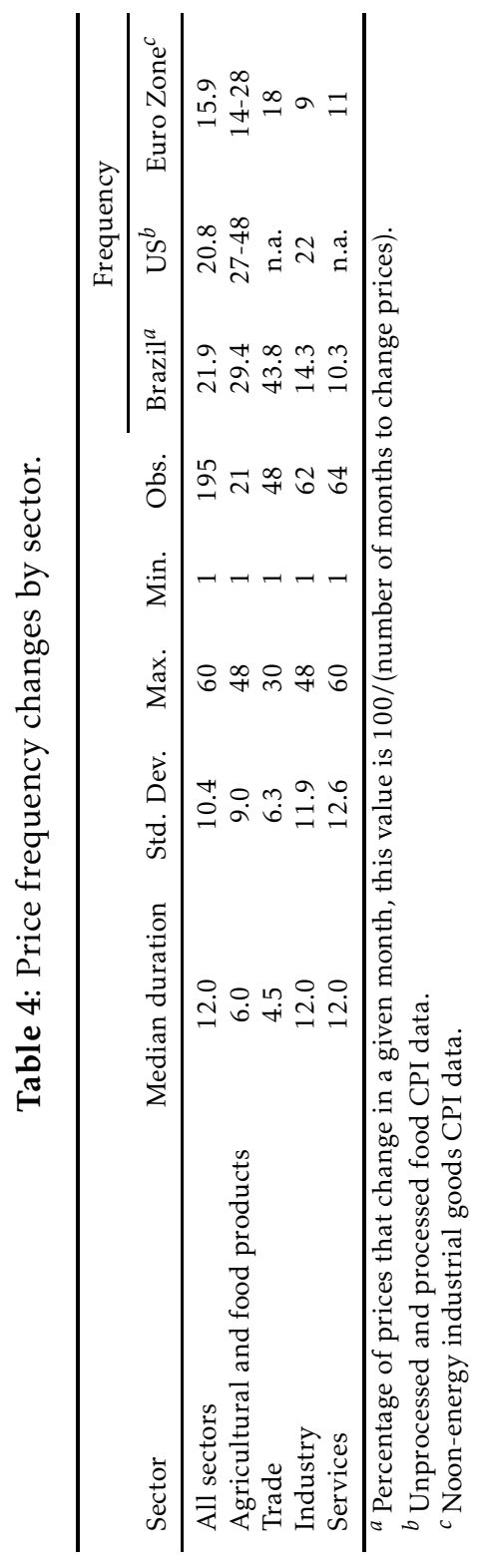




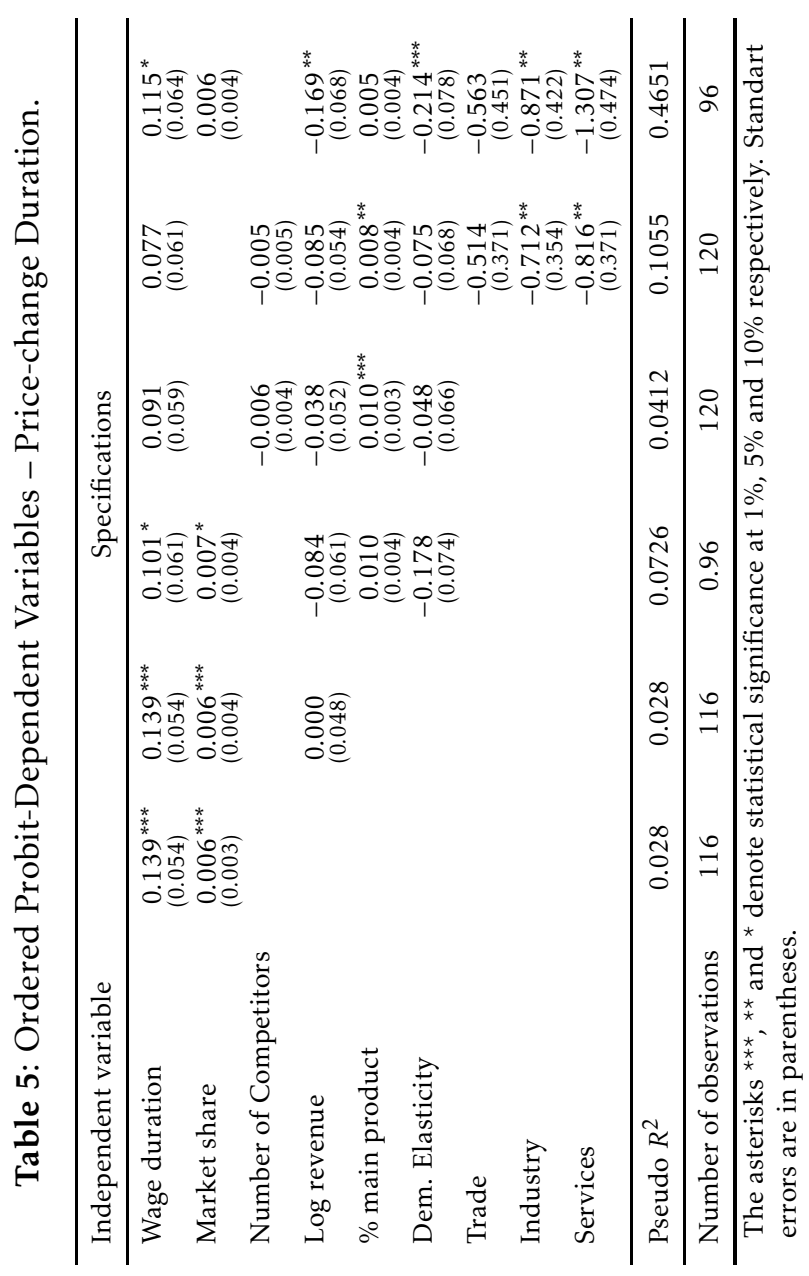




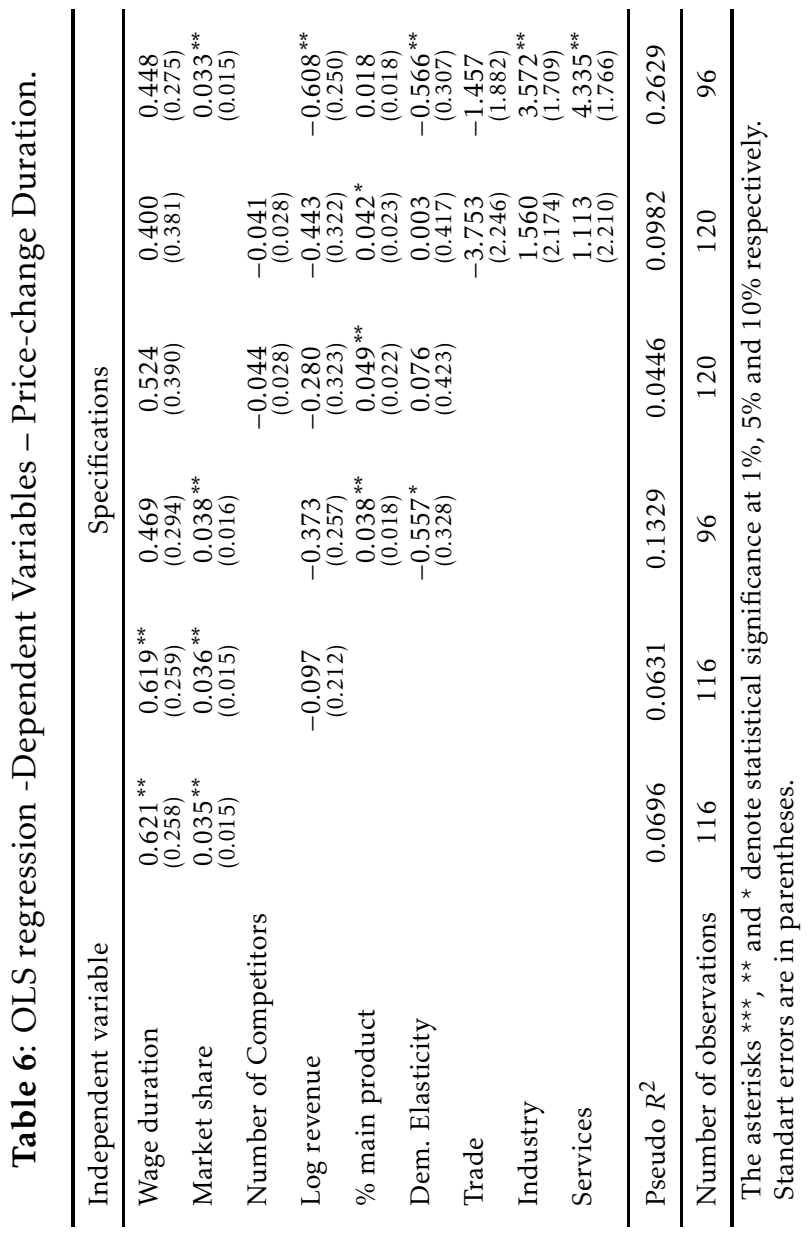


(2005) for Spanish companies, with regard to the signs and significance of competition, firm size and sector dummy variables.

\section{Conclusion}

The paper studied price-setting policies, using as micro-evidence survey data for 281 Brazilian companies. The analyses demonstrate interesting stylized facts, some already observed in other micro-evidence studies for the euro area and the US. The empirical results help an understanding of commonlyused macroeconomic modeling for monetary policy evaluation, particularly those models that imply nominal rigidities. New research on the topic has two equally productive veins: investment in theoretical pricing-rule models that replicate empirical stylized facts, and the further exploration of empirical determinants of different price-setting policies across firms.

\section{Bibliography}

Alvarez, G. \& Julián, L. (2008), 'What do micro price data tell us on the validity of the newkeynesian phillips curve?', Economics: The Open-Access, Open-Assessment E-Journal 2(2008-19).

Alvarez, L., Dhyne, E., Hoeberichts, M., Kwapil, C., Le Bihan, H., Lünnemann, P., Martins, F., Sabbatini, R., Stahl, H., Vermeulen, P. \& Vilmunen, J. (2006), 'Sticky prices in the euro area: A summary of new micro-evidence', Journal of the European Economic Association 4.

Alvarez, L. \& Hernando, I. (2005), Price setting behavior in spain: Stylized facts using consumerprice micro data, Working Paper Series 538, European Central Bank.

Angeloni, I., Aucremanne, L., Ehrmann, M., Galí, J., Levin, A. \& Smets, F. (2006), 'New evidence on inflation persistence and price stickiness inthe euro area: Implications for macro modeling', Journal of the European Economic Association 4(2-3), 562-574.

Bonomo, M. \& Carvalho, C. (2004), 'Endogenous time-dependent rules and inflation inertia', Journal of Money, Credit and Banking 36(6), 1015-1041.

Calvo, G. (1983), 'Staggered prices in a utility-maximizing framework', Journal of Monrtary Economics 12, 383-398.

Gagnon, G. (2007), Price setting during low and high inflation: Evidence from mexico, International Finance Discussion Papers 896, Board of Governors of the Federal Reserve System.

Gali, J. \& Gertler, M. (2007), 'Macroeconomic modeling for monetary policy evaluation', Journal of Economic Perspectives 21(4), 25-45.

Hoeberichts, M. \& Stockman, A. (2004), Pricing behavior of dutch companies: Main results from a survey. mimeo.

Kiley, M. T. (2000), 'Endogenous price stickiness and business cycle persistence', Journal of Money, Credit and Banking 32(1), 28-52. 
Nakamura, E. \& Steinsson, J. (2008), 'Five facts about prices: A reevaluation of menu costs models', The Quarterly Journal of Economics 123(4), 1415-1464.

Panzar, J. C. \& Willig, R. D. (1977), 'Economies of scale in multi-output production', The Quarterly Journal of Economics 91(3), 481-493.

Panzar, J. C. \& Willig, R. D. (1981), 'Economies of scope', The American Economic Review 71(2), pp. 268-272.

URL: $h t t p: / / w w w . j s t o r . o r g / s t a b l e / 1815729$

Romer, P. (1990), 'Endogenous technological change.', Journal of Political Economy 98, 71-102. 